\title{
$\underline{\mathrm{L} \& \mathrm{~S}}$ Cadernos
}

Cadernos de Linguagem e

Sociedade

Qualis A2 - eISSN 2179-4790 ISSN 0104-9712

ARTIGO

\section{O DISCURSO RELIGIOSO NO DEBATE SOBRE GÊNERO E SEXUALIDADE}

(Religious discourse about gender and sexuality)

Vicentina Ramires ${ }^{1}$

(Universidade Federal Rural de Pernambuco)

Lucas Henrique Silva ${ }^{2}$

(Universidade Federal Rural de Pernambuco)

Roseana Medeiros ${ }^{3}$

(Universidade Federal Rural de Pernambuco)

Recebido em: fevereiro de 2020

Aceito em: julho de 2020

DOI: $10.26512 /$ les.v21i2.29547

\footnotetext{
${ }^{1}$ Professora Associada do Departamento de Letras e do Programa de Pós-graduação em Estudos da Linguagem da UFRPE. Doutorado em Linguística (UFPE). Pós-doutorado em Linguística Aplicada (UECE/Sorbonne). E-mail: vicentinaramires@terra.com.br

${ }^{2}$ Graduando do curso de Letras da Universidade Federal Rural de Pernambuco. Bolsista PIBIC 2018-2019. E-mail: lucas.henriquesilva@icloud.com

${ }^{3}$ Professora Associada do Departamento de Ciências Sociais da UFRPE. Doutorado em Serviço Social (UFPE). E-mail: rosemedeiros@uol.com.br.
} 


\title{
RESUMO
}

Com base na ACD, este estudo tem como objetivo principal apresentar como alguns setores religiosos de orientação cristã têm contribuído para gerar/aumentar o preconceito contra as diferenças de gênero. Como objetivos específicos procuramos identificar nos discursos desses membros religiosos elementos indicadores de preconceito e analisar macro e microestruturas em que se manifestem formas de discriminação de diferentes grupos sociais. Foram analisados depoimentos, entrevistas e notícias do site religioso Gospel Prime. Os resultados demonstraram que muitos representantes religiosos, ao defenderem e reproduzirem discursos discriminatórios, contribuem fortemente para a violência física ou simbólica sobre essas minorias.

Palavras-chave: ACD. Gêneros. Religião. Ideologia.

\begin{abstract}
Based on CDA, this study has as main objective to present how some religious sectors of Christian orientation have contributed to generate/increase prejudice against gender differences. As specific objectives we try to identify in the speeches of these religious members elements that indicate prejudice and analyze macro and microstructures in which forms of discrimination of different social groups are manifested. Testimonies, interviews and published in the religious site Gospel Prime were analyzed. The results showed that many religious representatives strongly contribute to physical or symbolic violence against these minorities, in defending and reproducing discriminatory discourse.
\end{abstract}

Keywords: ACD. Genders. Religion. Ideology.

\section{RESUMEN}

Basado en el ACD, este estudio tiene como objetivo principal presentar cómo algunos sectores religiosos de orientación cristiana han contribuido a generar / aumentar los prejuicios contra las diferencias de género. Como objetivos específicos tratamos de identificar en los discursos de estos miembros religiosos elementos que indican prejuicios y analizan macro y microestructuras en las que se manifiestan formas de discriminación de diferentes grupos sociales. Se analizaron testimonios, entrevistas y noticias del sitio religioso Gospel Prime. Los resultados mostraron que muchos representantes religiosos, al defender y reproducir discursos discriminatorios, contribuyen fuertemente a la violencia física o simbólica contra estas minorías.

Palabras clave: ACD. Géneros. Religión. Ideología.

\section{INTRODUÇÃO}

A despeito das leis mais recentes, que visam proteger os direitos de vários grupos sociais historicamente discriminados ${ }^{4}$ - para usar um termo ameno -, ainda há muito que se caminhar para que, de fato, sejam garantidas condições mínimas de dignidade, proteção, acesso, inclusão, entre outros direitos, àqueles que os têm negados.

Dentre esses grupos se incluem as pessoas de diferentes identidades de gênero, tais como homossexuais, bissexuais, transexuais, transgêneros, travestis, entre outras denominações ${ }^{5}$. Vítimas

\footnotetext{
${ }^{4} \mathrm{O}$ decreto $\mathrm{N}^{\mathrm{o}}$ 8.727, de 28 de abril de 2016, da Presidência da República, dispõe sobre o uso do nome social e o reconhecimento da identidade de gênero de pessoas travestis e transexuais no âmbito da administração pública federal direta, autárquica e fundacional.

${ }^{5}$ Em 2014, o Facebook disponibilizou em torno de 50 diferentes denominações de gêneros para escolha de seus usuários, incluindo "neutro".
} 
de diferentes e perversas formas de discriminação e violência, essas pessoas têm contra si a divulgação de discursos discriminatórios proferidos por grupos poderosos que regulam os comportamentos, tais como os discursos religiosos, principalmente aqueles proferidos por representantes do catolicismo (principalmente o ortodoxo) e protestantismo (seja o histórico ou o chamado neopentecostal), por exemplo.

Em nome da preservação da família, dos "bons costumes", da "palavra de Deus" e outros argumentos falaciosos, esses grupos religiosos, respaldados na força ideológica que têm ${ }^{6}$, censuram enfaticamente o uso das expressões "gênero" ou "orientação sexual", especialmente nos planos locais de educação ${ }^{7}$. Grave tem sido a posição da CNBB (Conferência Nacional dos Bispos do Brasil), que, em 2015, em suas Seções Regionais, divulgou um documento conjunto ${ }^{8}$ em que se critica a inclusão de itens que valorizam a diversidade de gêneros nos planos estaduais e municipais de educação, advertindo sobre os "riscos da introdução da "ideologia de gênero" como norteadora da educação no país, além de acusar a "ideologia de gênero" de distorcer o conceito de homem e mulher?.

O trecho seguinte da nota produzida pelo Conselho Episcopal da seção REGIONAL SUL 1/CNBB, de São Paulo, assinada por Dom Odilo Pedro Scherer (Presidente), Dom Moacir Silva (Vice-Presidente), e Dom Tarcísio Scaramussa (Secretário), dá uma ideia precisa sobre a posição da CNBB como um todo em relação a essa temática:

A "ideologia de gênero" subverte o conceito de família, que tem seu fundamento na união estável entre homem e mulher, ensinando que a união homossexual é igualmente núcleo fundante da instituição familiar.

As consequências da introdução dessa ideologia na prática pedagógica das escolas contradiz [sic] frontalmente a configuração antropológica de família, transmitida há milênios em todas as culturas. Isso submeteria as crianças e jovens a um processo de esvaziamento de valores cultivados na família, fundamento insubstituível para a construção da sociedade.

Diante dessa grave ameaça aos valores da família, esperamos dos governantes do Legislativo e Executivo uma tomada de posição que garanta para as novas gerações uma escola que promova a família, tal como a entendem a Constituição Federal (artigo 226) e a tradição cristã, que moldou a cultura brasileira. ${ }^{10}$

\footnotetext{
${ }^{6}$ Ver Althusser e o conceito marxista de aparelhos ideológicos de Estado, dentre os quais a Igreja se destaca.

${ }^{7}$ Gênero e diversidade sexual nas escolas: uma questão de direitos humanos, por Vanessa Alves Vieira, Bernardo Fonseca Machado, Michele Escoura Bueno e Ana Paula Meirelles Lewin — publicado 17/07/2015. In: https://www.cartacapital.com.br/sociedade/genero-e-diversidade-sexual-nas-escolas-uma-questao-de-direitoshumanos-6727.html

${ }^{8}$ Esses documentos podem ser encontrados na íntegra no site da CNBB: http://www.cnbb.org.br/.

${ }^{9}$ Em 2011, foi aprovada pelo Supremo Tribunal Federal (STF) a união homoafetiva.

${ }^{10}$ Cardeal Dom Odilo Pedro Scherer, Presidente do Conselho Episcopal Regional Sul 1 - CNBB; Dom Moacir Silva, Vice-Presidente do Conselho Episcopal Regional Sul 1 - CNBB; Dom Tarcísio Scaramussa, Secretário do Presidente do Conselho Episcopal Regional Sul 1 - CNBB. 2015 (CNBB).
} 
A primeira Conferência Nacional de Políticas Públicas de Lésbicas, Gays, Travestis e Transexuais (2008), o lançamento de um novo Programa Nacional de Direitos Humanos (PNDH-III - 2009) e o Plano Nacional de Educação (PNE-2010) geraram reações dos atores políticos religiosos.

Uma cartilha elaborada pelo vereador evangélico Samuel Pereira (PR), distribuída nas escolas de Uberaba, na região do Triângulo Mineiro, em 2016, visava a orientar pais e estudantes sobre a proibição das discussões de "ideologias de gênero" nas escolas. Com o título " "ideologia de gênero" - Entenda o risco que você e seus filhos estavam correndo", a cartilha “orienta" a população sobre o perigo de organizações tentarem destruir a família tradicional. Em um dos pontos em que se critica explicitamente a "ideologia de gênero" apresenta-se a foto de uma mulher com os dizeres: "Isso é um absurdo!"11. A lei foi aprovada em novembro, e religiosos comemoraram a proposta, sobretudo Carlos Wilton, presidente do Conselho de Pastores de Uberaba, ao afirmar que foi uma "vitória da família".

Essa questão não tem apenas dimensão local, como pode parecer, quando a proposta é apresentada por um vereador de uma cidade do interior de Minas Gerais. Na verdade, propostas como essa chegam ao âmbito nacional, a exemplo de inúmeras outras elaboradas pela bancada evangélica no Parlamento. Dados levantados com base em pesquisa do DIAP ${ }^{12}$ (Departamento Intersindical de Assessoria Parlamentar) apontam que a bancada evangélica titular eleita em 2014 era composta por 87 deputados/as federais e 3 senadores, num total de 90 parlamentares. Considerando o total de 513 deputados federais no Congresso Nacional, a bancada de evangélicos corresponde, entre 2014 e 2018, ao percentual de 17\% dos parlamentares. Nas eleições de 2018 a bancada evangélica apresenta pequeno aumento na comparação com o pleito anterior (2014). Foram eleitos ou reeleitos 84 deputados identificados com as demandas, crenças e convicções deste segmento de interesse informal e suprapartidário na Câmara Federal. No Senado, os evangélicos mais do que dobraram a representação: de 3 para 7 parlamentares. Esses são números expressivos para tomada de decisões de natureza "religiosa".

De modo similar, considerando as formas abrangentes de divulgação de ideias, utilizando as redes sociais e divulgando em site "especializado" para esse fim, o autodenominado "conselheiro cristão", Paulo Cícero, apresenta uma lista de conselhos para os homossexuais ${ }^{13}$ :

1. Arrependa-se da prática homossexual.

\footnotetext{
11 Alunos de Uberaba recebem cartilha evangélica contra ideologia de gênero. In: http://www.correiobraziliense.com.br/app/noticia/brasil/03/06/2016.

12 Ver em: http://www.diap.org.br/ . Publicado em 17 Outubro 2018, 21:14.

13 Disponível em: http://www.conselheirocristao.com.br/2011/09/o-homossexualismo-do-ponto-de-vista.html. Acesso em: mar. 2017.
} 
2. Peça ajuda de pessoas que eram homossexuais, mas que agora estão livres pelo Poder de Deus.

3. Não tente usar a Palavra de Deus para se justificar, pois esta prática é odiável diante do Deus vivo.

4. Entregue a sua vida a Jesus, pois ninguém te ama como Ele.

5. Não fique indignado com Deus por ele condenar a sua prática errada, pois afinal de contas Ele é Deus.

6. Se teus pais não conseguem aceitar o fato de você ser homossexual, não os odeie por isto, pois eles estão certos, porém talvez não saibam como se expressar.

7. Não tente deixar esta prática sozinho, recorra depressa a Deus e peça a Ele forças.

8. Procure a igreja mais próxima de sua casa, e permita que o Espírito de Deus fale ao seu coração.

9. Não endureça o seu coração quando entender que é preciso se arrepender desta prática.

É nesse contexto que o termo "ideologia de gênero" tem sido utilizado, conforme reiteram Reis e Eggert (2017, p. 17), "por quem defende posições tradicionais, reacionárias e até fundamentalistas em relação aos papéis de gênero do homem e da mulher", tal como Scala (2012) ${ }^{14}$, que, ao definir o que considera ser "ideologia de gênero", defende que seu fundamento principal e falso é o seguinte:

"o sexo seria o aspecto biológico do ser humano, e o gênero seria a construção social ou cultural do sexo. Ou seja, que cada um seria absolutamente livre, sem condicionamento algum, nem sequer o biológico, para determinar seu próprio gênero, dando-lhe o conteúdo que quiser e mudando de gênero quantas vezes quiser. Agora, se isso fosse verdade, não haveria diferenças entre homem e mulher - exceto as biológicas; qualquer tipo de união entre os sexos seria social e moralmente boas, e todas seriam matrimônio; cada tipo de matrimônio levaria a um novo tipo de família; o aborto seria um direito humano inalienável da mulher, já que somente ela é que fica grávida; etc. Tudo isso é tão absurdo, que só pode ser imposto com uma espécie de "lavagem cerebral" global [...] O gênero destrói a estrutura antropológica íntima do ser humano [...] (SCALA, 2012).

Esses são alguns exemplos de como se expressam os discursos que visam garantir a dominação, o poder e a manutenção das desigualdades. É preciso ter claro que essas visões são ideologicamente construídas, de forma a se perpetuarem as formas de discriminação e opressão de um grupo sobre outro. Uma vez que o poder depende da conquista do consenso e não apenas de recursos para o uso da força, a ideologia tem importância na sustentação de relações de poder.

Assim que este estudo tem como objetivo principal apresentar, com base nos postulados da Análise Crítica de Discursos, como alguns setores religiosos, sobretudo aqueles de orientação cristã, têm contribuído para gerar/aumentar o preconceito contra as diferenças de gênero.

\footnotetext{
${ }^{14}$ Disponível em: https://pt.zenit.org/articles/ideologia-de-genero-neototalitarismo-e-a-morte-da-fami-lia/. Acesso em: 24 jan. 2020.
} 
Estabelecemos os seguintes objetivos específicos para o desenvolvimento desta pesquisa: a) Identificar nos discursos orais, escritos e imagéticos, produzidos por membros religiosos de igrejas de orientação cristã elementos verbais e não-verbais indicadores de discriminação. b) Analisar macro e microestruturas semânticas utilizadas pelo autor/produtor do texto em que se manifestem, explícita ou implicitamente, formas de discriminação de diferentes grupos sociais.

\section{GÊNERO, DISCURSO E IDEOLOGIA}

A literatura apresenta uma vasta fonte de pesquisa de autores/as que abordam o conceito de gênero enquanto instrumento teórico e empírico para a análise das relações sociais. Esse conceito se apresenta como um meio de distinguir a prática sexual (determinado pela natureza biológica do sexo feminino e masculino) dos papéis sociais (divisão sexual do trabalho, por exemplo), identidades e comportamentos opostos atribuídos aos homens e às mulheres na sociedade. As relações de gênero, assim como as de classe ou de etnia, são imbricadas pelo contexto social, cultural, político e econômico, ou seja, são construções históricas, portanto, multilineares e mutáveis. Em síntese:

Estabelecidos como um conjunto objetivo de referências, os conceitos de gênero estruturam a percepção e a organização concreta e simbólica de toda a vida social. Na medida em que essas referências estabelecem distribuições de poder (um controle ou um acesso diferencial aos recursos materiais e simbólicos), o gênero torna-se implicado na concepção e construção do próprio poder (SCOTT, 1995, p. 88).

O determinismo biológico, que embasa a discriminação entre gêneros, primordialmente, pode ser entendido como o conjunto de teorias segundo as quais a posição ocupada por diferentes grupos nas sociedades, comportamentos e variações das habilidades, capacidades, padrões cognitivos e sexualidade humana derivam de limites ou privilégios inscritos na constituição biológica, ou seja, nos corpos sexuados (MACEDO, 2003). Ressaltemos, como o fazem os estudos pós-estruturalistas sobre gêneros, que a estrutura de gênero age e se inscreve através de corpos sexuados, mas a ideia de dois sexos só tem sentido porque esses significados são requeridos primordialmente pelas estruturas de gêneros. Assim que é preciso entender, tal como Judith Butler defende, que o gênero nem sempre se constituiu de maneira coerente ou consistente nos diferentes contextos históricos, além de não poder ser reduzido seu entendimento ao resultado causal do sexo nem pode ser tratado tão aparentemente fixo quanto o sexo, mas, sim, culturalmente constituído. Portanto, para Butler (2016, p. 26):

[...] não há razão para supor que os gêneros também devam permanecer em número de dois. A hipótese de um sistema binário dos gêneros encerra implicitamente a 
crença numa relação mimética entre gênero e sexo, na qual o gênero reflete o sexo ou é por ele restrito.

$\mathrm{Na}$ verdade, relações afetivo-sexuais entre pessoas do mesmo sexo/gênero é uma construção moderna, uma vez que os termos usados para designar um ou outro gênero não têm o mesmo sentido nos diferentes períodos da história. Daí que o significado do termo identidade de gênero não se restringe a formas biológicas, nem a práticas sexuais, mas compreende a relação entre sexo, gênero, prática sexual e desejo.

Outro exemplo é o que ocorre com o termo homoafetividade, que, segundo Lomando \& Wagner (2009, p. 11):

[...] surge como alternativo à homossexualidade, com o objetivo de designar o afeto das relações entre pessoas do mesmo sexo/gênero, embasando-se na constatação dos relacionamentos duradouros, dos bens compartilhados, elos afetivos e parentalidade; substitui-se o sufixo sexual para afetividade como dispositivo possibilitador de reflexão psicossocial.

Da mesma forma que os usos linguísticos para designar os diferentes gêneros tomaram feitios e sentidos diferentes ao longo da história, as ciências médicas também desempenharam papel importante na fixação de conceitos discriminatórios sobre pessoas de gêneros diferentes aos da concepção binária e heteronormativa. Foucault (1984) ilustra bem essa questão, em entrevista à revista canadense Body Politic:

No movimento homossexual, por exemplo, a definição médica de homossexualidade constituiu-se em um instrumento muito importante para combater a opressão da qual era vítima a homossexualidade no fim do século XIX e início do XX. Esta medicalização, que foi um meio de opressão, tem sido também um instrumento de resistência, já que as pessoas podem dizer: "se somos doentes, então por que nos condenam, nos menosprezam?", etc. É claro que este discurso nos parece hoje bastante ingênuo, mas para a época ele foi muito importante ${ }^{15}$.

É preciso ter clareza de que a estrutura de gênero é ideológica e hegemônica, porque frequentemente não se apresenta como dominação, mas como consensual e aceitável numa comunidade. Para que haja consenso e aceitação, os grupos poderosos executam um consistente processo de operação ideológica em que estratégias típicas de construção simbólica garantem o funcionamento de relações de dominação, nem sempre explícitas. Para dar conta da compreensão desses mecanismos, os estudos críticos de discursos surgem com o objetivo de investigar como a

\footnotetext{
15 "Michel Foucault, une interview: sexe, pouvoir et la politique de la identité". ("Michel Foucault, an interview: sex, power and the politics of identity"; entrevista com B. Gallagher e A. Wilson, Toronto, junho de 1982; trad. F. DurantBogaert). The advocate, no 400, 7 de agosto de 1984, p. 26-30 e 58. Esta entrevista estava destinada à revista canadense Body politic.
} 
desigualdade social é expressa, sinalizada, constituída, legitimada e, também, desconstruída, por meio do uso da linguagem (ou no discurso). A desconstrução desses discursos é tarefa da Análise Crítica de Discursos (doravante, ACD), cujo interesse particular centra-se na relação entre linguagem, ideologia e poder. A ACD pode, então, ser definida como um campo dentro dos estudos críticos da linguagem fundamentalmente interessado em analisar relações estruturais - transparentes ou veladas - de discriminação, poder e controle manifestas na linguagem. Assim é que a Teoria Social do Discurso se baseia em uma percepção da linguagem como parte irredutível da vida social dialeticamente interconectada a outros elementos sociais (RAMALHO; RESENDE, 2006), ou seja, o discurso é moldado pela estrutura social, mas é também constitutivo dessa estrutura social.

Para garantir a dominação, o poder e a manutenção das desigualdades, van Dijk (2008) assevera que grupos poderosos controlam o discurso público pela concessão ou não do acesso a esses discursos - acesso definido pelo contexto (cenário, ações, participantes, representações mentais), pelas estruturas do texto (gêneros textuais, atos de fala) e pelos temas (macroestruturas semânticas). Em consequência, esse discurso controla as mentes e as ações dos indivíduos, que tendem a aceitar crenças, desde que produzidas pelas consideradas fontes autorizadas, confiáveis ou críveis, ou pelo desconhecimento desses indivíduos sobre o discurso ou informação a que são expostos.

Esse ponto é confirmado por Resende (2017, p. 17), ao chamar atenção para o fato de que "reconhecer a existência também de pressões pela manutenção de configurações estruturantes, o que se associa à noção de poder como controle. Discutir poder como controle exige uma apreensão do funcionamento da linguagem na sociedade, e esse argumento [...] sustenta a relevância dos estudos críticos do discurso." É dessa forma que são formados e/ou reformulados os modelos mentais e as representações sociais, conforme postulam Chouliaraki e Fairclough (1999, p. 37):

Discurso, portanto, se apresenta de duas maneiras nas práticas: práticas são parcialmente discursivas (falar, escrever, etc, é apenas um modo de ação), mas elas são também discursivamente representadas. Na medida em que tais representações ajudam a sustentar relações de dominação nessas práticas, elas são ideológicas ${ }^{16}$.

É com base nessas considerações que os estudos do discurso são críticos e, metodologicamente, segundo van Dijk (2008), devem observar alguns dos seguintes critérios:

a) o estudo das relações de dominação pelo grupo dominado e do seu interesse;

b) o uso das experiências dos grupos dominados para avaliar o discurso dominante;

c) a denúncia da ilegitimidade das ações discursivas do grupo dominante;

\footnotetext{
16 Tradução nossa. No original: Discourse therefore figures in two ways within practices: practices are partly discursive (talking, writing, etc. is one way of acting), but they are also discursively represented. In so far as such representations help sustain relations of domination within the practice, they are ideological.
} 
d) a formulação de alternativas viáveis aos discursos dominantes.

Relações de poder e dominação, entretanto, podem ser discursivamente confrontadas, num embate dinâmico para assegurar ou desafiar os interesses em jogo. Exatamente esta é a tarefa da ACD na perspectiva de gênero: examinar como o poder e a dominação são discursivamente produzidos e/ou confrontados de formas variadas pelas representações textuais de práticas sociais de gênero e por meio de estratégias interacionais de conversação (LAZAR, 2005).

Bolívar (2010) propõe que as pesquisas em análise crítica do discurso devem ser abordadas sobre uma perspectiva dialógica, ou seja, no caso específico da América Latina, há que se ir além da análise de textos em contextos, mas tentar ler a sociedade para explicar como as pessoas, as lideranças, os cidadãos e a mídia contribuem para moldar a dinâmica política e social do país em que o pesquisador vive. E argumenta que:

[...] não se pode ignorar todo o processo [do evento], uma vez que, em sua dinâmica, há pessoas que tomam decisões que afetam outras pessoas. Suponho que, para explicar ambos, os textos e os eventos, noções fundamentais de diálogo e avaliação são necessárias. (BOLÍVAR, 2010, p. 218). ${ }^{17}$

Para que sejam, pois, observados alguns critérios para uma metodologia da análise de discursos de gêneros, dois conceitos são indispensáveis para a ACD: o conceito de poder, e o conceito de ideologia, que abordaremos neste estudo por responderem com mais propriedade as questões levantadas para a análise de nosso corpus.

Thompson (1990) aponta que o conceito de ideologia surgiu no século XVIII na França e tem sido utilizado numa gama de funções e significados ao longo desses mais de dois séculos. Para ele, ideologia refere-se a processos e formas sociais no interior dos quais e por meio dos quais circulam formas simbólicas no mundo social. Dessa forma, o estudo da ideologia tenta explicar como o significado é construído e transmitido através de diferentes formas simbólicas, e o conceito de poder surge como fundamental para essa compreensão. Embutidas nas práticas discursivas, as ideologias são muito eficazes quando se tornam naturalizadas e atingem o status de 'senso comum' (FAIRCLOUGH, 2001). Nesse caso, alguns aspectos ou níveis do texto e do discurso que podem ser investidos ideologicamente são especialmente os semânticos (pressuposições, metáforas e coerência). Ou seja, é exatamente nos discursos que a eficácia da ideologia se consolida, pois esta deriva do fato de que se confere às palavras não só um sentido, mas também um poder: poder de persuasão, de convocatória, de consagração, de estigmatização (HAIDAR, 2000). Uma vez que o poder depende da

\footnotetext{
17 Tradução nossa. No original: “As an analyst, one can focus on any of these moments but cannot ignore the whole process because in its dynamics there are people who make decisions that affect other people. It has been my assumption that in order to explain both, the texts and the events, the fundamental notions of dialogue an evaluation are needed."
} 
conquista do consenso e não apenas de recursos para o uso da força, a ideologia tem importância na sustentação de relações de poder.

Baseando-se no conceito de hegemonia elaborado por Gramsci ${ }^{18}$ (1978; 1987), Fairclough (2001) preocupa-se em acentuar a noção de discurso como "modo de prática política e ideológica", e ressalta:

O discurso como prática política estabelece, mantém e transforma as relações de poder e as entidades coletivas [...] entre as quais existem relações de poder. $\mathrm{O}$ discurso como prática ideológica constitui, naturaliza, mantém e transforma os significados do mundo de posições diversas nas relações de poder (FAIRCLOUGH, 2001, p. 94).

Considerando-se o discurso nessa perspectiva, um fenômeno que é objeto de análise de estudiosos é a naturalização do discurso, conforme postula Thompson (1990), ou seja, uma estratégia para legitimar, dissimular, unificar, fragmentar e reificar relações de dominação, o que é bastante perigoso, uma vez que pode levar indivíduos a reproduzirem ideologias que os prejudicam a si ou a outros.

O poder, que envolve relações de diferença - e, particularmente, os efeitos dessas diferenças nas estruturas sociais -, é sinalizado não somente pelas formas gramaticais presentes em um texto, mas também pelo controle que uma pessoa exerce sobre uma ocasião social através do gênero textual (WODAK, 2004). Mas é preciso ter claro, como alerta Foucault (1979, p. 86), que o poder "é tolerável somente na condição de que mascare uma grande parte de si mesmo. Seu sucesso é proporcional à sua habilidade para esconder seus próprios mecanismos”. E como esse mascaramento se realiza nas práticas de linguagem? Hanks (2008, p. 152) responde essa pergunta: "Por serem encaixados em formas de produção textual, de orientação estética e de modos de recepção, fatos sociais historicamente específicos se tornam invisíveis e inquestionáveis".

Em outras palavras, muitas vezes as formas como os discursos são apresentados materializam e naturalizam formas de controle do poder social - controle de um grupo sobre outros grupos e seus membros - pela força potencial, locucionária, ilocucionária e perlocucionária do texto. A conquista do consentimento é, portanto, um trabalho discursivo, alicerçado em aparelhos ideológicos da sociedade, principalmente os órgãos da mídia (impressa ou eletrônica) e por setores da Igreja ${ }^{19}$.

\footnotetext{
18 Ver: GRAMSCI, Antonio. Obras Escolhidas. São Paulo: Martins Fontes, 1978; GRAMSCI, Antonio. Concepção dialética da história. 7. ed. Rio de Janeiro: Civilização Brasiliense, 1987.

${ }^{19}$ Utilizamos neste estudo a palavra Igreja com "I" maiúsculo sempre que esta for tratada como instituição, tal como Escola, Estado, Saúde Pública, entre outras designações.
} 


\section{GÊNERO E RELIGIÃO}

Ao longo da história a Igreja vem desempenhando papel fundamental na manutenção do discurso discriminatório no que diz respeito a gêneros sociais. Na história das civilizações esse tema sempre fez parte das pautas de discussões filosóficas, políticas, educacionais, familiares, dentre tantas, quase todas permeadas pela noção religiosa de "pecado", ou de "permissão". A religião é a ideologia que possibilita aos homens permanecerem em seus papéis e a não tentarem mudanças sociais, porque tais situações representam a vontade de Deus. Nesse caso a religião constitui-se como força conservadora que impossibilita a realização de significativas transformações sociais. Ela aquieta o homem, torna-o passivo, anula sua força de revolta. Em geral, tem sido a base de todas as discussões a ideia da criação divina do mundo para que este fosse povoado a partir da procriação do homem e da mulher.

É possível elencar, ao longo da história, algumas concepções de segmentos religiosos sobre a questão de gêneros, mas importa esclarecer que não é o objetivo deste estudo fazer uma apresentação detalhada da história das religiões no mundo, nem apresentar todas as vertentes do cristianismo, que são muitas, com diferenças abissais. Interessa-nos, aqui, apresentar, principalmente, duas dessas vertentes: o catolicismo e protestantismo (este último, em especial, o chamado neopentecostal), pela expressividade de seus postulados em relação ao tema do nosso estudo e pelo grande número de seguidores no Brasil e no mundo.

Trazendo do passado o entendimento que havia sobre o que hoje tratamos como gêneros, voltemos à Grécia antiga, em que era comum o amor entre homens, além de instituído na Babilônia e Canaã. Os guerreiros de Tebas e Esparta, por exemplo, antes dos combates, faziam sacrifícios para Eros, deus do amor, e posteriormente se relacionavam ${ }^{20}$. Entretanto, em se tratando de gêneros, a única referência feita nas religiões, ainda àquela época, é à homossexualidade, especificamente à do sexo masculino. Mulheres, por exemplo, não eram sequer mencionadas como uma possibilidade de serem identificadas com outro gênero.

Ainda hoje, para muitas religiões, relações afetivas entre pessoas de mesmo sexo são consideradas como desvio de conduta, com punições bastante rigorosas, tais como prisão, multa ou castigo físico, podendo chegar até a morte, como é o caso de alguns países islâmicos. Entre os judeus, a homossexualidade é considerada um pecado grave e chegou a ser punida com pena de morte, com base no Torá. Os homossexuais foram perseguidos durante muito tempo, principalmente com a

\footnotetext{
${ }^{20}$ Religão x Gays: O que cada segmento religioso pensa sobre os homossexuais. Leonardo Campos* em $\underline{31 / 01 / 2013}$. https://disponivel.uol.com.br/acapa/revista/religao-X-gays-o-que-cada-segmento-religioso-pensa-sobre-oshomossexuais/13/38/21499.
} 
expansão do cristianismo, e até hoje, a despeito de alguns pequenos avanços nos discursos de uma ou outra igreja de orientação cristã, a perseguição a diversidades de gêneros é expressiva. O catolicismo, por exemplo, reprova a homossexualidade e utiliza passagens da Bíblia, conforme interpretações que lhe convêm. Seu maior representante, o Papa Francisco, tem feito declarações menos negativas digamos assim - sobre essa questão. Em entrevista recente para o Jornal El Mundo, da Espanha, declarou: "Se uma pessoa é gay e procura Jesus, e tem boa vontade, quem sou eu para julgá-la? O Catecismo diz que não se deve marginalizar essas pessoas por isso. Elas devem ser integradas à sociedade. O problema não é ter esta tendência. Devemos ser irmãos" ${ }^{21}$. Para o Espiritismo, o espírito não tem sexo e um mesmo espírito pode, em diferentes encarnações, habitar um corpo de um homem ou mulher, mas a ala conservadora revela posições bastante graves em relação ao tema, tal como se manifesta Divaldo Franco, um dos maiores nomes do movimento espírita brasileiro, com inúmeros livros publicados, que avalia a questão como "Imoralidade ímpar", e “Aberração”, opinião fortemente contestada pelos espíritas progressistas ${ }^{22}$.

Mas talvez não haja, entre as religiões cristãs, aquelas que mais fortemente discriminem as diferenças de gêneros como as Igrejas Protestantes, que chegaram ao Brasil a partir de 1850, com um discurso ideológico liberal representando os valores burgueses (individualismo, progresso, disciplinas profissionalizantes nas escolas), atraindo os filhos da pequena burguesia ascendente. Buscando implantar uma mentalidade europeia de modernidade, as missões protestantes encontravam-se ligadas às Igrejas Metodistas, Presbiterianas, Batistas, Luteranas, Anglicanas, com um discurso de forte contradição ao catolicismo hegemônico ibérico, considerado atrasado. O Catolicismo era considerado como uma religião que se afastou dos Evangelhos, ou seja, uma religião pagã, por seus rituais, pela pompa das missas, pela adoração aos santos. Com essa visão, portanto, eles seriam os genuínos cristãos, colocando-se numa posição de superioridade. Marcadas pelo fundamentalismo moral e doutrinário, enfatizando a moral pietista (proveniente do Luteranismo, que mostrava a necessidade de renunciar ao mundo, de buscar a santificação, a conversão individual), essas igrejas pregavam a austeridade e a negação dos "prazeres mundanos" Atualmente a chamada “intelectualidade protestante" constata um avanço do processo de "pentecostalização" das Igrejas históricas missionárias brasileiras, com um crescimento acelerado das Igrejas Pentecostais, surgidas no início do século XX, nos EUA. A expressão pentecostal é proveniente do termo Pentecostes (momento em que o Espírito Santo desce para os seguidores de Jesus), conforme se encontra no livro

\footnotetext{
21 Disponível em: http://arqrio.org/formacao/detalhes/127/palavras-do-papa-sobre-homossexualidade-sao-baseadas-nocatecismo. Acesso em: 15 fev. 2019.

${ }_{22}$ Disponível em: https://jornalggn.com.br/noticia/espiritas-progressistas-respondem-a-entrevista-coletiva-de-divaldofranco-e-haroldo-dutra. Acesso em: jan. 2019.
} 
bíblico Atos, capítulo 2, sendo entendida como uma renovação espiritual e uma retomada da Igreja Primitiva Cristã. As Igrejas tradicionais começam a incorporar práticas pentecostais com louvores, cultos de libertação e cura e a glossolalia (capacidade de falar em línguas estranhas, como um processo de transe).

No Brasil, as religiões evangélicas possuem diferentes vertentes, que podem ser caracterizadas basicamente em protestantismo histórico e protestantismo pentecostal e neopentecostal. Coexistindo com as Igrejas Pentecostais, mas com uma identidade própria, em meados dos anos 70 e 80 do século XX surge o movimento Neopentecostal, cujos doutrinadores e integrantes buscam vivenciar sua fé de forma sobrenatural, enfatizando revelações divinas, milagres, lutas maniqueístas entre o bem e o mal, batalhas espirituais e incorporações do Espírito Santo. Essas experiências religiosas possuem uma forte conotação emocional. Nessas Igrejas a homossexualidade se encontra em um nível inferior no tocante aos considerados pecados sexuais. Essa interpretação é pautada em versículos tanto do Antigo como Novo Testamento, e são muito citadas as passagens de Sodoma e Gomorra.

Mesquita e Perucchi (2015) esclarecem a diferença da visão da homossexualidade entre Igrejas Protestantes tradicionais e as Igrejas Pentecostais. As primeiras fazem a ligação entre homossexualidade e problemas psíquicos relativos a pessoas que não aceitam sua sexualidade biológica, dada por Deus, e os levaria a muitas angústias e tensões. As Igrejas Pentecostais e Neopentecostais, por seu lado, tendem a demonizar a homossexualidade, vendo-os como possuídos ou influenciados pelo diabo, cuja salvação só se encontraria na aceitação a Cristo, que os levaria à libertação. Portanto, nessas Igrejas (que agora predominam no Brasil) a homossexualidade não somente é um pecado contra Deus, como também é fruto de possessão demoníaca, que deve ser, na visão dessas, combatida e eliminada.

\section{Metodologia}

\subsection{Delimitação espaço-temporal do estudo}

Desde a década de 1990, ativistas e promotores de direitos LGBT ${ }^{23}$ (como eram designados esses grupos sociais) vêm tentando firmar a identidade de gênero como categoria de não discriminação nas leis internacionais. Considerando, pois, esse percurso histórico do movimento

\footnotetext{
${ }^{23}$ A sigla LGBT (lésbicas, gays, bissexuais, travestis e transexuais) passou a ser adotada pelos movimentos sociais de reivindicação de direitos e cidadania das minorias sexuais somente a partir da Primeira Conferência Nacional GLBT, em 2008. Neste artigo, optamos por acrescentar à sigla a inicial I (intersexo) e o sinal + (que abrigaria outras tantas denominações de gêneros já identificados ou a identificar).
} 
social LGBT, em 2004, o governo federal lançou o Programa Brasil Sem Homofobia (BSH) e em 2008 foi realizada a I Conferência Nacional LGBT. Não há até o presente momento no Brasil uma legislação sobre a criminalização da homofobia e transfobia, mas, na versão final do Plano Nacional de Direitos Humanos de 2010 (BRASIL, 2010) ${ }^{24}$, é tratada a temática da não discriminação a LGBT. É a partir desse marco temporal que esses discursos serão analisados.

\subsection{Os sujeitos do estudo}

As práticas discursivas que serão objeto de nossa análise virão, majoritariamente, de autoridades eclesiásticas evangélicas e católicas, veiculadas no Portal mencionado Gospel Prime, uma vez que os seguidores dessas duas igrejas representam a grande maioria da população do país, conforme dados apresentados na tabela seguinte do último Censo do IBGE (2010).

\begin{tabular}{|l|l|l|}
\hline Religião & \% em 2010 & Quantidade em 2010 (em milhões de pessoas) \\
\hline Católicos & 64,6 & 123,2 \\
\hline Evangélicos & 22,2 & 42,2 \\
\hline Outras religiões & 5,2 & 9,6 \\
\hline Sem religião & 8 & 15,3 \\
\hline
\end{tabular}

\subsection{Descrição do corpus}

O critério de escolha do material eletrônico, tais como blogs e similares, baseou-se no número expressivo de visualizações, o que demonstra a amplitude de divulgação das ideias neles contidas. Desta forma, as fontes coletadas para este estudo estão compiladas com base nas notícias veiculadas em um dos sites mais visitados para esta pesquisa, o "Gospel Prime" 25 . Segundo descrição no próprio site, em Quem somos²6, “O Portal cristão Gospel Prime nasceu em dezembro de 2008, com o objetivo de informar aos interessados, tudo o que acontece no universo evangélico, independentemente da denominação”. Por dispor de conteúdos de naturezas diversas, dentro desta temática de estudo, muitos deles “fundamentados", segundo o que está dito no próprio portal, por "grandes estudiosos", essa página tem sido muito importante para esta investigação, uma vez que, além de alcançar 3,5 milhões de visualizações mensais, do ponto de vista dos objetivos deste estudo, une muitas fontes de análise das categorias propostas pelos autores aqui aportados.

\footnotetext{
$24 \quad$ Ver versão eletrônica https://www.ohchr.org/Documents/Issues/NHRA/ProgrammaNacionalDireitosHumanos2010.pdf.

25 https://noticias.gospelprime.com.br/

${ }^{26}$ https://www.gospelprime.com.br/quem-somos/
} 
O corpus foi coletado pela indexação do termo "ideologia de gênero" na busca da aba de notícias do site Gospel Prime. Foram coletadas 32 notícias, organizadas, primeiramente, por ordem de relevância, considerando o período entre 2010 e 2018. Após a seleção, com base nas categorias já mencionadas, reduzimos o corpus para 14 notícias, organizadas em ordem cronológica. Em relação à autoria, observamos que a grande maioria das notícias vem apenas assinada com os dizeres "Por Redação", o que nos impede de identificar em que medida os possíveis autores são "grandes estudiosos", como se faz menção no portal ${ }^{27}$. Para facilitar a identificação, apresentamos os títulos das notícias de onde foram retirados os trechos a seguir analisados, os quais serão identificados de acordo com a numeração seguinte, antecedidos da letra N (Notícia):

1. "Homossexualidade não é um pecado pior que os outros", diz John Piper ( 26 de marco de 2015 por redação)

2. Ana Paula Valadão pede boicote à $\mathbf{C} \& A$ por apologia a "ideologia de gênero" ( 20 de maio de 2016 - Por Redação)

3. "ideologia de gênero" vai contra a razão e a ciência, diz Malafaia (30 de setembro de 2016 - Por Redação)

4. Pais impedem "ideologia de gênero" nas escolas (31 de julho de 2017 - Por Tiago Abreu)

5. Silas Malafaia diz que é ilegal ensinar "ideologia de gênero" nas escolas (12 de setembro de 2017 - Por Tiago Abreu)

6. George Soros: uma ameaça aos cristãos conservadores do Brasil (18 de setembro de 2017 - Por Redação)

7. Criadora da "ideologia de gênero" admite que contraria a Bíblia ( 2 de novembro de 2017 - Por Redação)

8. Pastores combatem "ideologia de gênero" com outdoors: "Uma questão de genética" (29 de novembro de 2017 - Por Redação)

9. “ideologia de gênero" é lixo moral”, alerta Ezequiel Teixeira (30 de novembro de 2017 - Por Redação)

10. Projeto internacional ajuda gays a deixarem a prática homossexual ( 29 de janeiro de 2018 - por Ana Souza)

11. Especialistas convocam Igreja a combater a "ideologia de gênero" (27 de abril de 2018 - Por Redação)

12. Cardeal denuncia que "ideologia de gênero" é parte de uma "nova religião" (31 de maio de 2018 - Por Redação)

13. Padre convoca católicos e evangélicos a se unirem contra "ideologia de gênero" (22 de outubro de 2017 - Por Redação)

14. Bispos rejeitam “ideologia de gênero" e aborto na África (30 de outubro de 2018 - Por Redação)

\section{ANÁLISE DOS DADOS}

Van Dijk (2008) sugere alguns procedimentos metodológicos para os estudos críticos do discurso que aqui tentaremos levar a cabo. Um deles, mais global, é a análise das macroestruturas semânticas, que são os tópicos ou temas dos textos, geralmente intencionais e controlados pelo

\footnotetext{
27 Três autores puderam ser identificados pelo próprio portal. Thiago Cortês é formado em Sociologia pela Fundação Escola de Sociologia e Política de São Paulo. Ele escreve em seu blog e tem artigos publicados nos sites Mídia Sem Máscara e Reaçonaria. Tiago Abreu, jornalista pela Universidade Federal de Goiás, é autor de textos pelo Gospel Prime desde 2016. Cris Beloni é jornalista, teóloga e pesquisadora apaixonada pela Bíblia. Desenvolveu um trabalho de Jornalismo Investigativo Bíblico e é autora do livro Derrubando Mitos.
} 
enunciador, expressos em títulos, resumos, sumários. Outro, mais local, é a análise das microestruturas semânticas, as quais dizem respeito às escolhas lexicais e sintáticas, às relações proposicionais e aos recursos extralinguísticos feitos pelo produtor do texto.

Considerando que a ideologia se opera e se consolida a partir de estratégias de construção simbólica (no caso, pelo discurso), que ajudam a manter estáveis relações de discriminação, dominação e poder, Thompson (1990) identifica estratégias presentes nos discursos de forma a legitimar, dissimular, unificar, fragmentar e reificar essas relações.

No nosso estudo, buscamos apresentar apenas três desses modos de operação ideológica: legitimação, dissimulação e reificação.

A "legitimação" se opera por meio de falácias argumentativas ou racionalização (por exemplo, apelos à legalidade, a bases jurídicas, científicas) e de narrativização (exigências de legitimação inseridas em histórias do passado que legitimam o presente, como as tradições, costumes e o habitus), ou seja, operam como construtos simbólicos da ideologia.

A “dissimulação" se concretiza por meio de ocultação, negação ou obscurecimento de relações de dominação, por estratégias de deslocamento contextual de termos e expressões, eufemismos ou figuras de linguagem, como metáforas, metonímias, sinédoques.

A "reificação" retrata situações transitórias tidas como permanentes e naturais, por meio da banalização de um determinado acontecimento.

Essas categorias são observadas na relação direta com a análise das macro e microestruturas discursivas já mencionadas, de forma a compor um quadro mais expressivo das formas de manifestação ideológica de discriminação nesses discursos.

Ao propor uma representação da teorização da linguagem na sociedade por meio de um mapa ontológico $^{28}$, Resende (2017, p. 28) observa que, apesar de não se pretender que os “empreendimentos investigativos em análise de discurso crítica sejam uma complexa análise de estruturas e suas implicações práticas, [...] certamente não podemos nos furtar a discutir e buscar compreender como esses elementos estruturantes incidem nos contextos investigados".

Ideologias arraigadas no senso comum são difíceis de serem percebidas e/ou combatidas. Os discursos discriminatórios - principalmente aqueles proferidos por “autoridades de poder", tais como os representantes das igrejas, - são incorporados por aqueles que os reproduzem, sugerindo que as ideologias embutidas nas práticas discursivas podem ser muito eficazes quando se tornam naturalizadas e atingem o status de "senso comum". Exemplos dessa natureza foram encontrados em

\footnotetext{
${ }^{28}$ Sobre esse mapa e outros modelos de análise crítica do discurso, ver artigo de RESENDE, V. Reflexões teóricas e epistemológicas quase excessivas de uma analista obstinada. In: RESENDE, V.; REGIS, J. Outras perspectivas em análise de discurso crítica. Campinas, SP: Pontes, 2017a, p.11-52.
} 
grande número nos sites "oficiais" de natureza religiosa. Vejamos alguns textos retirados do repositório mencionado, associados às categorias das análises que estamos utilizando neste trabalho.

Algumas estratégias de construção simbólica/operação da ideologia foram observadas nas notícias apresentadas no site investigado. Organizamos os trechos para análise, conforme estão descritas essas categorias, com base em Thompson (1990), e salientamos que alguns podem estar relacionados a mais de uma categoria, e serão, por isso, apresentados em duplicidade. Todos os trechos estão identificados com a letra N (Notícia) e o número correspondente à lista de notícias já apresentada.

\subsection{Legitimação - Relações de dominação são representadas como legítimas.}

a) Falácias Argumentativas (apelos à legalidade, a bases jurídicas, falsa causa).

$\mathrm{N} 3$ - "A "ideologia de gênero" é uma crença - não é uma ciência - que os dois sexos, masculino e feminino, é uma construção social e cultural. Na verdade, a "ideologia de gênero" é a ausência de sexo”, explica [Silas Malafaia] (...), que é formado em psicologia, [e] que pela ciência a sexualidade - em diferentes espécies - tem três funções principais: dualismo (contrários); complementariedade e fecundação.

N5 - Nós estamos vivendo uma verdadeira inversão de valores e uma tentativa de impor à sociedade aquilo que as leis brasileiras, de maneira clara, mostram que é ilegal (...) E você deve buscar seu direito se alguma escola está ensinando ou tá com cartilhas, ou com qualquer instrumento pedagógico querendo colocar na goela do teu filho a ideologia de gênero", orientou o líder. (...) Malafaia usou como base o artigo 229 da Constituição Brasileira de 1988 (...)

Nesses dois exemplos, dois argumentos de "legalidade" e "autoridade" foram utilizados para fundamentar as afirmações: o artigo 229 da Constituição ${ }^{29}$ e a formação do autor ("formado em psicologia”). O referido artigo, por si só, não sustenta esse argumento, pois não trata da especificidade desse tema, e a formação do autor não pode ser suficiente para ser usada como garantia de "verdade" da afirmação.

De forma semelhante os exemplos seguintes (N11, N12 e N13) apresentam características dos enunciadores para fundamentar as afirmações preconceituosas. Os termos destacados "especialistas", "influente", "grande influência" dão essa dimensão de legitimidade. Assim, expressões como "O influente cardeal alemão Gerhard Müller” (N12), “O padre Roger Luís, com grande influência na rede de TV Canção Nova” (N13), "John Piper, conhecido teólogo e autor de livros" (N1) reforçam a ideia de que pessoas cuja credibilidade é reconhecida parece ser suficiente para fazer parecer verdade irrefutável aquilo que dizem. Assim, discursos religiosos e científicos se

\footnotetext{
${ }^{29}$ Art. 229. Os pais têm o dever de assistir, criar e educar os filhos menores, e os filhos maiores têm o dever de ajudar e amparar os pais na velhice, carência ou enfermidade. (Constituição Federal Brasileira -1988)
} 
alternam ou se complementam para desqualificar as relações de gêneros diferentes daquelas heteronormativas, de forma a cercear os direitos dessa população.

N1 - John Piper, conhecido teólogo e autor de livros, foi confrontado com uma questão que é recorrente na abordagem que os cristãos fazem sobre o movimento gay.

N11- Especialistas convocam Igreja a combater a "ideologia de gênero" - Cinco líderes cristãos denunciam o marxismo cultural como um perigo imediato - "(...) marxismo cultural que prega a destruição de família e da vida, conforme defendia o antigo Manifesto Comunista."

N12 - O influente cardeal alemão Gerhard Müller, Prefeito Emérito da Congregação para a Doutrina da Fé do Vaticano, está denunciando que a ascensão da "ideologia de gênero"” já possui características de uma "nova religião". Também enfatizou que "na "ideologia de gênero" podemos ver dezenas de gêneros, porém o ser humano foi criado como homem e mulher: esta é a nossa natureza, e a vontade de Deus Criador se expressa nesta natureza".

N13 - O padre Roger Luís, com grande influência na rede de TV Canção Nova, convocou católicos e evangélicos a se unirem contra "ideologia de gênero" (...)

b) Universalização (interesses específicos são apresentados como interesses gerais).

N8 - Quem passa pelas ruas de Blumenau nos últimos dias nota a presença de outdoors com os dizeres "XX e XY - uma questão de genética. Família projeto de Deus". A ação midiática foi promovida pela Ordem dos Ministros do Evangelho de Blumenau (Omeblu). (...) O pastor Leonardo Aluisio, presidente da Omeblu, reforça que o objetivo dos outdoors é reforçar o conceito bíblico e criacionista de família.

c) Narrativização (exigências de legitimação inseridas em histórias do passado que legitimam o presente).

N2-A cantora Ana Paula Valadão, que também é pastora da Igreja Lagoinha, em Belo Horizonte, usou as redes sociais para iniciar uma campanha de boicote. Ela afirmou que foi tomada de uma "santa indignação" por causa da nova campanha das lojas C\&A. Chamada "misture, ouse, experimente”. (...) No comercial em questão, a C\&A propõe que o próximo dia dos namorados seja o "dia dos misturados".

N10 - Projeto internacional ajuda gays a deixarem a prática homossexual (...) A missão desse programa, fundado há 8 anos, é promover uma alternativa para pessoas com Atração pelo Mesmo Sexo - AMS. Através de atividades variadas o indivíduo é impactado diariamente e consegue descobrir a sua própria heterossexualidade subjacente, ou pelo menos diminuir sua erotização pelo mesmo sexo. [Depoimento]: "Em 2010, voltei para Cristo, depois de ter vivido um estilo de vida gay ativo por mais de 12 anos (a partir de Ensino Médio). Desde então, tenho experimentado grande cura, restauração e redução significativa de atração por pessoas do mesmo sexo, através da oração, missa diária, terapia reparativa, e cura das emoções feridas", diz.

\subsection{Dissimulação - Relações de dominação são ocultadas, negadas ou obscurecidas.}

a) Deslocamento (deslocamento contextual de termos e expressões).

N7 - Criticada sobretudo pelos cristãos que defendem a família e entendem que a ideologia defendida por ela é algo nocivo para a sociedade, a filósofa admite: "É uma crítica feita pelo Catolicismo de direita... Se você baseia a sua visão de mundo na Bíblia, então, a ideia de gênero vai ser mesmo ofensiva."

b) Eufemização (valoração positiva de instituições, ações ou relações).

N11 - Gabriella Ortiz destacou que se faz cada vez mais necessário o debate sobre a influência das agendas globalistas no âmbito da igreja, sendo urgente uma "resposta pastoral" e a produção 
de literatura teológica e bíblica sobre essas novas realidades do mundo que "jaz no maligno", mas que continua "amado por Deus".

c) Tropo (sinédoque, metonímia, metáfora, comparação)

N3 - "Os esquerdopatas entenderam que o último reduto de autoridade é a família. Então destroça a família para criar uma sociedade de informes para ser dominada por uma elite política”.

N1 - John Piper, conhecido teólogo e autor de livros, foi confrontado com uma questão que é recorrente na abordagem que os cristãos fazem sobre o movimento gay. "A homossexualidade é pior para a sociedade que outros pecados?". Em sua resposta, divulgada no programa de rádio online que mantém, ele explicou que outros pecados como ganância e orgulho são muito mais comuns que o comportamento homossexual.

\subsection{Reificação - Retratação de uma situação transitória como permanente e natural.}

a) Nominalização/Passivação (concentração da atenção em certos temas em prejuízo de outros, com apagamento de atores e ações)

N6 - George Soros: uma ameaça aos cristãos conservadores do Brasil

Documentos da Open Society Foundations mostram que bilionário investe pesado na "ideologia de gênero". Aquele seu amiguinho "lacrador", que repete o discurso sobre "ideologia de gênero" aprendido em sala de aula com professores ligados a movimentos de esquerda, mal sabe que está fazendo o jogo de um dos homens mais ricos do planeta, com fortuna avaliada em 25 bilhões de dólares.

Em todos os textos analisados predominam as falácias (argumentos ou raciocínios que, embora incorretos, podem ser psicologicamente persuasivos), como forma estratégica de operação de ideologia, principalmente a falácia denominada de Argumentum ad Verecumdiam (ou argumentum magister dixit) (COPI, 1978), que significa apelo à autoridade ou argumento de autoridade. No caso deste estudo, o nome de Deus, os trechos da Bíblia, as leis, as pessoas consideradas importantes, como as autoridades eclesiásticas e científicas, são elementos fortes na sustentação dos argumentos apresentados nesses fragmentos.

Falácias de falsa causa (tomar como causa de um efeito algo que não é sua causa real) ou de argumento pela ignorância (Argumentum ad Ignorantiam - proposição sustentada pela falta de prova da verdade ou falsidade dessa mesma proposição) foram observadas em grande medida nessas notícias. A afirmação de que "o feminismo abre uma 'guerra dos sexos"”(N11) é um exemplo de falácia de falsa causa, bem como o argumento de que existe um "marxismo cultural que prega a destruição de família e da vida, conforme defendia o antigo Manifesto Comunista"(N11) pode ser eficaz, quando o discurso é endereçado a interlocutores que não tiveram acesso a leituras de ou sobre Marx, que jamais defendeu essa ideia.

Escolhas lexicais e estratégias sintáticas (VAN DIJK, 2008) para desqualificar aqueles que defendem igualdade de direitos para pessoas LGBTI+, podem ser vistas em exemplos tais como 
“esquerdopatas” (N3), “jaz no maligno” (N11), “Aquele seu amiguinho 'lacrador'” (N6), “comportamento homossexual” N1).

Fica claro, no texto, que a homossexualidade é um pecado com diferentes níveis de gravidade, a depender da base que fundamenta o argumento de cada participante da construção desse discurso. Para esse fim, a Bíblia é ampla e fervorosamente citada. Mas é interessante observar como trechos desse livro são utilizados como regras de conduta e valor de verdade - principalmente as passagens do antigo testamento - de forma descontextualizada e para sustentar ideias em momentos pontuais e convenientes à funcionalidade discursiva na ordem dos discursos religiosos (MESQUITA; PERUCCHI, 2016).

O entendimento de que a homossexualidade é uma prática antinatural à criação divina, principalmente por não garantir a reprodução da espécie, permeia praticamente todos esses discursos aqui apresentados. Quase todos os entrevistados ou defensores desse entendimento nas notícias analisadas acreditam na "cura" do que chamam de "prática homossexual", como é visto no depoimento N10, em que um dos assistidos por uma organização especializada em ajudar "gays $a$ deixarem a prática homossexual” (...) “consegue descobrir a sua própria heterossexualidade subjacente”: “(...) tenho experimentado grande cura, restauração e redução significativa de atração por pessoas do mesmo sexo, através da oração (...)".

\section{CONSIDERAÇÕES FINAIS}

Os direitos das minorias, de modo geral, têm sido rejeitados ou combatidos pelos setores conservadores da sociedade. Particularmente, essa rejeição se intensifica em níveis até violentos quando se trata dos direitos das pessoas LGBTI+, por pertencerem a categorias consideradas “impuras", "pecaminosas". A grande questão é que, conforme ressaltam Natividade \& Oliveira, (2009, p. 132), essa rejeição "está embasada no temor do impacto que conquistas como a parceria civil possam ter sobre normas hegemônicas sustentadas em concepções cristãs de família e conjugalidade."

Ainda que rejeitem o rótulo de homofóbicos, esses discursos revelam o desprezo por essas minorias, e induzem, em certa medida, atos homofóbicos, que vão desde a valorização daqueles considerados "normais" pelos grupos sociais prestigiados ao rebaixamento daqueles que são considerados "anormais" por esses mesmos grupos. Ainda que haja avanços na esfera pública para o reconhecimento dos direitos da população LGBTI+ (resultados de sua luta, ressalte-se), na esfera privada ainda prevalecem a produção e a difusão de estereótipos negativos sobre a diversidade sexual. 
Poderosa como quase nenhuma outra instituição, a Igreja, ao defender e reproduzir discursos tais como esses apresentados neste estudo, contribui fortemente para a violência, física ou simbólica, sobre aqueles que deveriam ser protegidos pela sociedade, como todos os demais cidadãos. Não se pode desconsiderar o fato de que discursos de fundo religioso procuram orquestrar consensos em defesa de valores que acreditam deverem ser universalmente difundidos e aceitos, principalmente por meio de utilização de falácias argumentativas que exaltam "a fé e a moral cristã”. Na verdade, esses discursos não fazem outra coisa senão ajudarem a manter estáveis relações de discriminação, dominação e poder, para calar as vozes das minorias de todas as ordens, que reivindicam o reconhecimento e a promoção da equidade de direitos.

O portal Gospel Prime, a despeito de se considerar " $100 \%$ cristão" e "manter a imparcialidade e oferecer informações precisas, objetivas e com credibilidade", como está definido na sua caracterização, tem contribuído para manter e fortalecer mecanismos cotidianos de controle de condutas, de forma a garantir que os "valores" cristãos e o modelo idealizado de família não sejam ameaçados por um fenômeno concebido como perigoso, que é a luta pela igualdade de direitos de todos - bandeira levantada pela população LGTBI+ em todos os fóruns onde são capazes de erguêla.

Contudo, esses valores hegemônicos não impedem de todo que outras vozes e iniciativas dissidentes no interior das igrejas cristãs sejam ouvidas, questionadas, analisadas. Exemplo disso é a emergência do movimento de "igrejas inclusivas", católicas ou protestantes, que vêm se contrapondo aos discursos conservadores, representando um avanço na luta por direitos à igualdade de todos os seres humanos, seja qual for o gênero.

\section{REFERÊNCIAS}

BOLÍVAR, A. A change in focus: from texts in contexts to people in events. Journal of Multicultural Discourses, Londres, v. 5, n. 3, p. 213-226, 2010.

BRASIL. Programa Nacional de Direitos Humanos (PNDH-3) / Secretaria de Direitos Humanos da Presidência da República. Ver. e atual. Brasília: SDH/PR, 2010.

BUTLER, Judith. Problemas de gênero. 10. ed. Rio de Janeiro: Civilização Brasileira, 2016.

CHOULIARAKI, Lilie; FAIRCLOUGH, Norman. Discourse in Late Modernity: rethinking critical discourse analysis. Edinburgh: Edinburgh University Press, 1999.

COPI, I. Introdução à lógica. 2. ed. São Paulo: Mestre Jou, 1978.

FAIRCLOUGH, Norman. Discurso e mudança social; tradução, revisão técnica e prefacio: Izabel Magalhaes. Brasília: Editora Universidade de Brasília, 2001.

FOUCAULT, Michel. Microfísica do Poder. Organização e tradução de Robert Machado. Rio de Janeiro: Edições Graal, 1979. 
FOUCAULT, Michel. Michel Foucault, uma entrevista: sexo, poder e a política da identidade. Entrevista com B. Gallagher e A. Wilson.Tradução de Wanderson Flor do Nascimento. Revista Verve, n. 20, 2011.

GRAMSCI, Antonio. Obras Escolhidas. São Paulo: Martins Fontes, 1978.

GRAMSCI, Antonio. Concepção dialética da história. 7. ed. Rio de Janeiro: Civilização Brasiliense, 1987.

GRAMSCI, Antonio. Os Intelectuais e a Organização da Cultura. 3. ed., Editora Civilização Brasileira - Rio de Janeiro, 1979.

HAIDAR, Julieta. El poder y la magia de la palavra. El campo del análisis del discurso. In LUGO, Norma del Rio (coord.) La producción textual del discurso científico. México: Universidad Autónoma Metropolitana, 2000. p. 33 a 65.

HANKS, Williams F. Língua como prática social: das relações entre língua, cultura e sociedade a partir de Bourdieu e Bakhtin. São Paulo: Cortez, 2008.

LAZAR, Michelle. Politicizing Gender in Discourse: feminist critical discourse analysis as political perspective and praxis. In: LAZAR, Michelle (ed). Feminist Critical Discourse Analysis: Gender, Power and Ideology in Discourse. New York: Palgrave Macmillan, 2005. p. 1-28.

LOMANDO, Eduardo; WAGNER, Adriana; GONCALVES, Jaqueline. Coesão, adaptabilidade e rede social no relacionamento conjugal homossexual. Psicol. teor. prat., São Paulo, v. 13, n. 3, p. 96-109, dez. 2011.

MACÊDO, GOIACIRA N. S. A construção da relação de gênero no discurso de homens e mulheres, dentro do contexto organizacional. Dissertação (Mestrado em Psicologia Social) Universidade Católica de Goiás, 2003.

MACHADO, Maria das Dores Campos. O discurso cristão sobre a ideologia de gênero. Revista Estudos Feministas, Florianópolis, v. 26, n. 2, p. e47463.

MESQUITA, Daniele Trindade; PERUCCHI, Juliana. Não apenas em nome de Deus: discursos religiosos sobre homossexualidade. Psicol. Soc., Belo Horizonte , v. 28, n. 1, p.105-114, abr. 2016.

NATIVIDADE, M. T.; OLIVEIRA, L. Sexualidades ameaçadoras: religião e homofobia(s) em discursos evangélicos conservadores. Sexualidad, Salud y Sociedad, v. 2, p. 121-161, 2009.

RAMAlHO, Viviane; RESENDE, Viviane. Análise de Discurso Crítica. São Paulo: Contexto, 2006.

REIS, Toni e EGGERT, Edla. Ideologia de gênero: uma falácia construída sobre os planos de educação brasileiros. Educ. Soc., Campinas, v. 38, n. 138, p. 9-26, jan./mar. 2017

RESENDE, V. Reflexões teóricas e epistemológicas quase excessivas de uma analista obstinada. In: RESENDE, V.; Regis, J. Outras perspectivas em análise de discurso crítica. Campinas, SP: Pontes, 2017a, p.11-52.

SCALA, J. Ideologia de gênero: o neototalitarismo e a morte da família. Zenit. 31 jan. 2012. Disponível em: https://pt.zenit.org/articles/ideologia-de-genero-neototalitarismo-e-a-morte-da-familia/. Acesso em: 24 jan. 2020.

SCOTT, Joan. Gênero: uma categoria útil de análise histórica. Educação \& Realidade, v. 20, n. 2, p. 71-99, jul./dez. 1995.

STACCONE, Giuseppe. Filosofia da Religião. O Pensamento do Homem Ocidental. Vozes Petrópolis, 1984. 
THOMPSON, John B. Ideology and modern culture. Cambridge: Polity Press, 1990.

VAN DIJK, Teun A. Discurso e Poder. São Paulo: Contexto, 2008.

WODAK, Ruth. Do que trata a ACD - um resumo de sua história, conceitos importantes e seus desenvolvimentos. In: Linguagem em (Dis)curso, Tubarão, v. 4, n.esp, p. 223-243, 2004. 